\title{
Latent overhydration and nocturnal hypertension in diabetic nephropathy
}

\author{
H.Mulec ${ }^{1}$, G. Blohmé ${ }^{2}$, K. Kullenberg ${ }^{1}$, G. Nyberg ${ }^{3}$, S. Björck ${ }^{3}$ \\ ${ }^{1}$ Department of Nephrology, Northern Älvsborg Hospital, Trollhättan, Sweden \\ ${ }^{2}$ Diabetes Unit, Department of Internal Medicine, Sahlgren's Hospital, University of Göteborg, Sweden \\ ${ }^{3}$ Department of Nephrology, Sahlgren's Hospital, University of Göteborg, Göteborg, Sweden
}

\begin{abstract}
Summary With the aim of studying the diurnal variation in blood pressure in relation to degree of fluid retention, 24-h ambulatory blood pressure monitoring was performed in 31 insulin-dependent diabetic patients with nephropathy. The extracellular volume was calculated from the distribution volume of ${ }^{51} \mathrm{Cr}-$ EDTA after a single injection. The study population was arbitrarily divided into two groups, depending on their extracellular volume. Group 1 included 15 patients with a lower extracellular volume and group 2, 16 patients with a higher extracellular volume. Ambulatory blood pressure was measured with a portable monitor using an oscillometric technique. In all patients, the mean $\pm \mathrm{SD} 24$-h ambulatory blood pressure was $135 / 79 \pm 14 / 7 \mathrm{mmHg}$. Day and night-time blood pressures were $136 / 81 \pm 14 / 7$ and $133 / 75 \pm 17 / 8$, respectively $(p<0.02)$. The ambulatory blood pressure was $135 / 80 \pm 14 / 7$ in group 1 and $136 / 78 \pm 15 / 6 \mathrm{mmHg}$ in group 2. The nocturnal
\end{abstract}

change in blood pressure was significantly greater in group 1 than in group 2, $-9 /-9 \pm 10 / 5 \mathrm{~mm} \mathrm{Hg}$ and $1 /-3 \pm 10 / 6 \mathrm{mmHg}$, respectively $(p=0.005 / 0.01)$. There were no other significant differences between the groups than the diurnal blood pressure pattern. There were significant correlations between day ambulatory blood pressure and night ambulatory blood pressure and 24-h ambulatory blood pressure and urinary albumin excretion. There was no correlation between auscultatory clinic blood pressure on the one hand and albuminuria on the other. Latent fluid retention therefore may contribute to nocturnal hypertension in diabetic nephropathy. [Diabetologia (1995) 38: 216-220]

Key words Insulin-dependent diabetes mellitus, diabetic nephropathy, ambulatory blood pressure, circadian variation, extracellular volume.
During the past 10 years the prognosis for diabetic nephropathy has improved considerably, mainly due to effective antihypertensive treatment, which is probably a major factor in arresting the decline in kidney function $[1,2]$. Recently, an abnormal 24-h blood pressure profile with a reduced nocturnal decline in blood pressure has been reported in patients with diabetic nephropathy [3-5]. The rele-

Received: 14 February 1994 and in revised form: 16 August 1994

Corresponding author: Dr. S. Björck, Department of Nephrology, Sahlgren's Hospital S-41345 Göteborg, Sweden Abbreviations: ECV, Extracellular volume; IDDM, insulin-dependent diabetes mellitus; ABP, ambulatory blood pressure. vance of this finding is unknown, but it is possible that nocturnal hypertension adversely affects the kidney. The causes of this blunted day/night blood pressure variation are also unknown. Several mechanisms have been proposed however, such as poor metabolic control, fluid retention and autonomic dysfunction [5].

The mechanism is likely to be multifactorial, but fluid retention is an attractive explanation. It seems logical that mobilisation of fluid which is peripherally lodged while in the recumbent position would cause central accumulation of fluid leading to elevated blood pressure during the night. To investigate this, we determined the extracellular volume (ECV) in insulin-dependent diabetic (IDDM) patients with nephropathy and studied its relationship 
Table 1. Clinical and laboratory characteristics of 31 patients with diabetic nephropathy divided in two groups according to extracellular volume

\begin{tabular}{|c|c|c|}
\hline & Group 1 & Group 2 \\
\hline $\bar{n}$ & 15 & 16 \\
\hline Male/female & $8 / 7$ & $11 / 5$ \\
\hline Age (years) & $45 \pm 8$ & $44 \pm 7$ \\
\hline $\begin{array}{l}\text { Duration of diabetes } \\
\text { (years) }\end{array}$ & $31 \pm 7$ & $32 \pm 6$ \\
\hline $\begin{array}{l}\text { Daytime albuminuria } \\
(\mu \mathrm{g} / \mathrm{min})\end{array}$ & $171(52-550)$ & $373(195-724)$ \\
\hline $\begin{array}{l}\text { Night-time albuminuria } \\
(\mu \mathrm{g} / \mathrm{min})\end{array}$ & $129(36-457)$ & $356(154-813)$ \\
\hline Body weight (kg) & $77 \pm 15$ & $71 \pm 9$ \\
\hline Serum sodium (mmol/l) & $134.4 \pm 3.1$ & $135.7 \pm 3.0$ \\
\hline Haemoglobin $(g / 1)$ & $125 \pm 13$ & $115 \pm 20$ \\
\hline Haemoglobin $\mathrm{A}_{1 \mathfrak{c}}(\%)$ & $8.8 \pm 1.3$ & $9.3 \pm 1.9$ \\
\hline Insulin dose (daily units) & $47 \pm 17$ & $48 \pm 17$ \\
\hline GFR $\left(\mathrm{ml} \cdot \min ^{-1} \cdot 1.73 \mathrm{~m}^{-2}\right)$ & $38 \pm 17$ & $40 \pm 29$ \\
\hline $\mathrm{ECV}(\mathrm{ml})$ & $1391 \pm 281$ & $1614 \pm 248$ \\
\hline ECV (\% of bodyweight) & $18.2 \pm 1.6$ & $22.8 \pm 1.2$ \\
\hline Betablockade treatment $(\%)$ & 60 & 44 \\
\hline Furosemide (mg daily) & $145(40-750)$ & $143(20-1750)$ \\
\hline
\end{tabular}

The values are given as means \pm SD except for albumin excretion which is geometric means (95\% confidence intervals) and furosemide dose which is given as median with range. Group 1 included the 15 patients with the lower ECV and group 2 , the 16 patients with the higher ECV. There were no significant differences between groups except for ECV

to the night/day ratio in blood pressure, determined with ambulatory blood pressure (ABP) measurements.

\section{Subjects and methods}

Thirty-one IDDM patients with nephropathy were studied. The patients were selected so that a wide range of renal function was represented. The mean glomerular filtration rate was 39 (range $8-123$ ) $\mathrm{ml} \cdot \mathrm{min}^{-1} \cdot 1.73 \mathrm{~m}^{-2}$. The patients had a mean age of $44 \pm 7$ years with onset of diabetes at a mean age of 13 years (range $4-26$ years). The mean duration of diabetes was $32 \pm 7$ years. The body weight was $74 \pm 12 \mathrm{~kg}$. All the patients had elevated urinary albumin excretion $(>20 \mu \mathrm{g}$ albu$\mathrm{min} / \mathrm{min}$ ) and many had been treated with antihypertensive therapy for many years. We did not classify the patients into micro- and macro-albuminuria because of discrepancies between albuminuria and glomerular filtration rate probably related to effective antihypertensive treatment. One patient had microalbuminuria $(70 \mu \mathrm{g} / \mathrm{min})$ and preserved glomerular filtration rate. One patient was treated with hydrochlorothiazide, the others with furosemide. The median furosemide dose was $160 \mathrm{mg}$ (range $20-1750 \mathrm{mg}$ ). Twenty-nine patients were treated with angiotensin converting enzyme inhibitors, 15 with beta blockers and 8 with calcium channel blockers. The patients were divided in two groups depending on $\mathrm{ECV}$; group 1 included the 15 patients with the lower ECV and group 2, the 16 patients with the higher ECV.

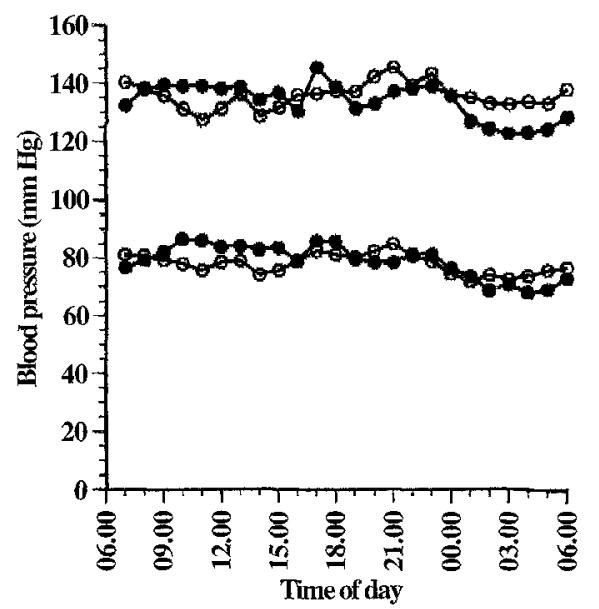

Fig. 1. 24-h profiles of mean systolic and diastolic blood pressure. Patients with extracellular volume in the lower range $\bullet$; patients with extracellular volume in the higher range $O$

Methods. Blood pressure was measured at 20-min intervals from 06.00 to 22.00 hours and at 30 -min intervals during the night. A lightweight portable automatic monitor based on the principal of oscillometry was used (SpaceLabs Model 90207; SpaceLabs, Redmont, Wash., USA) [6]. Day and night-time blood pressures were calculated from fixed times instead of actual bedtime. The daytime blood pressure was calculated as the mean of the readings between 07.00 and 10.00 hours and night-time blood pressure as the mean of the remaining readings. For comparison, mean blood pressures were also calculated as daytime between 12.00 and 04.00 hours and night-time blood pressure between 24.00 and 04.00 hours. The mean $24-\mathrm{h}$ blood pressure was calculated as the mean of the individual means calculated for each hour. Mean arterial blood pressure was calculated as diastolic blood pressure plus one-third of the difference between systolic and diastolic blood pressure. Clinical auscultatory blood pressure was measured as the mean of two recordings with a mercury manometer after $5 \mathrm{~min}$ in the supine position.

Haemoglobin $A_{1}$, serum electrolytes and urinary albumin excretion were measured by routine automated methods. Urinary albumin excretion was measured as day and night secretion based on the patients' own report of time for going to bed and rising.

Glomerular filtration rate was determined from the plasma disappearance of ${ }^{51} \mathrm{Cr}$-EDTA after a single injection [7]. The plasma concentrations of ${ }^{51} \mathrm{Cr}$-EDTA were measured at 180 , $183,200,220,240$ and $300 \mathrm{~min}$ after injection. ECV was calculated from these values according to Brøchner-Mortensen [8] and is presented as percent of the body weight. The normal value is $19.5 \%$ in men and $18.8 \%$ in women [9]. The ambulatory blood pressure equipment was given to the patient at the $\mathrm{ECV}$ determination and the recording was done at the earliest convenient time.

\section{Statistical analysis}

Results are presented as means \pm SD. Urinary albumin excretions are given as geometric means (antilog $95 \%$ confidence interval of the logarithms) and furosemide doses as medians (range) due to their skewed distribution. The study group was arbitrarily divided in two categories with 15 and 16 patients, respectively depending on their ECV. Group 1 included the 15 patients with the lower ECV and group 2, the 16 patients with the higher ECV. Differences between groups were as- 
Table 2. Blood pressure and heart rate in 31 patients with diabetic nephropathy divided in two groups according to extracellular volume

\begin{tabular}{llll}
\hline & Group 1 & Group 2 & $p$ value \\
\hline Daytime heart rate (beats/min) & $84 \pm 12$ & $87 \pm 13$ & 0.45 \\
Night-time heart rate (beats/min) & $75 \pm 8$ & $78 \pm 9$ & 0.21 \\
24-h blood pressure (mm Hg) & $135 / 80 \pm 14 / 7$ & $136 / 78 \pm 15 / 6$ & $0.8 / 0.6$ \\
Daytime blood pressure (mm Hg) & $138 / 83 \pm 13 / 8$ & $135 / 79 \pm 15 / 6$ & $0.6 / 0.3$ \\
Night-time blood pressure (mmHg) & $129 / 73 \pm 16 / 8$ & $137 / 76 \pm 18 / 8$ & $0.1 / 0.3$ \\
Heart rate night/day ratio & $1.12 \pm 0.07$ & $1.11 \pm 0.1$ & 0.8 \\
Systolic night/day ratio & $0.93 \pm 0.05$ & $1.01 \pm 0.07$ & 0.003 \\
Diastolic night/day ratio & $0.89 \pm 0.06$ & $0.96 \pm 0.08$ & 0.01 \\
\hline
\end{tabular}

Group 1 included the 15 patients with the lower ECV and group 2, the 16 patients with the higher ECV. The values are given as means $\pm \mathrm{SD}$

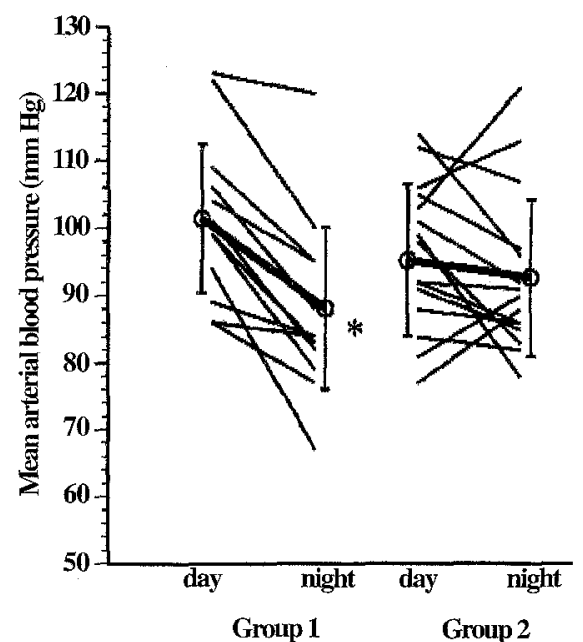

Fig. 2. Change from day to night in mean arterial blood pressure measured with ambulatory blood pressure monitoring in patients with low (group 1) or high (group 2) extracellular volume. Blood pressure was determined between 12.00 and 16.00 hours (day) and 24.00 and 04.00 hours (night). $* p=0.0007$

sessed by Wilcoxon's non-parametric method and $p<0.05$ was considered as significant. Spearman's rank correlation coefficient was used for correlations.

\section{Results}

Clinical data of both groups are given in Table 1 . The major results are given in Table 2 . The mean glomerular filtration rate was $39 \pm 24 \mathrm{ml} \cdot \mathrm{min}^{-1} \cdot 1.73 \mathrm{~m}^{-2}$ (range 8-123). The hourly blood pressures for the two groups are shown in Figure 1 . The mean $24-\mathrm{h}$ blood pressure in all patients was $135 / 79 \pm 14$ / $7 \mathrm{~mm} \mathrm{Hg}$. The day and night-time blood pressures were $136 / 81 \pm 14 / 7$ and $133 / 75 \pm 17 / 8$, respectively. Auscultatory clinic supine blood pressure was 151/ $87 \pm 21 / 10 \mathrm{~mm} \mathrm{Hg}$ which is higher than the daytime ambulatory blood pressure $(p<0.01)$.

In all patients, the blood pressure fell with $4 / 6 \pm 10 /$ $7 \mathrm{~mm} \mathrm{Hg}$ during the night $(p<0.02)$. In group 1 , both systolic and diastolic blood pressures fell significantly during the night $(p<0.001)$ but there was no signif- icant change in group 2. Blood pressure data from a more narrow time range $-4 \mathrm{~h}$ from noon and $4 \mathrm{~h}$ from midnight - gave an identical pattern (Fig.2). The change in blood pressure was $-13 /-13 \pm 8 /$ $7 \mathrm{~mm} \mathrm{Hg}$ in group 1 and $1 /-48 \pm 17 / 9 \mathrm{~mm} \mathrm{Hg}$ in group $2(p=0.003)$. The night/day ratio in mean arterial blood pressure was significantly correlated to $\mathrm{ECV}$ (rho $=0.39, p=0.03$ ). The heart rate fell significantly in both groups during the night $(p<0.001)$. There was no correlation between glomerular filtration rate or $\log$ furosemide dose and ECV (rho = -0.17 and 0.19 , respectively). In 12 patients with more preserved glomerular filtration rate $\left(>40 \mathrm{ml} \cdot \mathrm{min}^{-1}\right.$. $1.73 \mathrm{~m}^{-2}$ ) the night to day ratio in ambulatory mean arterial blood pressure was 0.87 and 0.95 , respectively $(p<0.01)$.

Half of the patients received beta blocking agents. This treatment did not seem to affect the night/day ratio of blood pressure as shown by a value of $0.95 \pm 0.06$ in those with and $0.94 \pm 0.09$ in those without beta blockade. Most patients took their antihypertensive drugs in the morning but seven patients had an evening dose. Three of these seven patients were in the group that had the highest nocturnal blood pressure fall. The night-time urine production in the group with high and low ECV was $1.3 \pm 0.5 \mathrm{ml} / \mathrm{min}$ and $21.1 \pm 1.1 \mathrm{ml} / \mathrm{min}$, respectively $(p=0.03)$. The daytime urine production did not differ between the groups $(1.6 \pm 0.9 \mathrm{ml} / \mathrm{min}$ vs $1.7 \pm 0.7 \mathrm{ml} / \mathrm{min}$ ).

There was no significant correlation between auscultatory clinic supine blood pressure and albuminuria $(r h o=0.03)$. Albuminuria during the day, the night, and over $24 \mathrm{~h}$ was significantly correlated to $\mathrm{ABP}$ during the corresponding period (rho $=0.7,0.5$ and 0.7 , respectively $p \leq 0.007$ ).

\section{Discussion}

In the present study, IDDM patients and nephropathy were selected so that a wide range of renal function was represented. We found no nocturnal decline in blood pressure in patients with relatively high 
ECV. In contrast, patients with lower ECV had an almost normal night/day blood pressure ratio.

The 24-h ABP was well-controlled, if conventional criteria for clinical blood pressure measurements are used but higher than the 24-h ABP values for normal population. In a meta analysis including 3476 normal subjects, the 24 -h blood pressure was $118 / 72 \mathrm{~mm} \mathrm{Hg}$ [10]. The daytime blood pressure was $123 / 76 \mathrm{~mm} \mathrm{Hg}$ and the night-time blood pressure $106 / 64 \mathrm{~mm} \mathrm{Hg}$. The ratios between night and day pressures were 0.87 for systolic and 0.83 for diastolic blood pressure.

The change in blood pressure associated with sleep has been described in several studies [11-14]. In healthy individuals $24-\mathrm{h}$ recordings have shown that blood pressure tends to be highest in the morning with a gradual decrease over the course of the day and is lowest (15-20\%) $2 \mathrm{~h}$ after the onset of sleep. This diurnal blood pressure pattern can be caused by variation in physical activity and by the influence of stress hormones. In patients with essential hypertension, the blood pressure pattern is similar to that found in normotensive subjects [12-13]. Secondary hypertension however, is often associated with a blunted nocturnal decline in blood pressure. This phenomenon has been found in hypertension of chronic renal failure, malignant hypertension pheochromocytoma, pre-eclamptic toxaemia, Cushing's syndrome and orthostatic hypotension [15].

Several investigators have found a reduced nocturnal decline in blood pressure in diabetic renal disease $[3-5,14]$. Hansen et al. [5] found a $7 \%$ nocturnal reduction of diastolic blood pressure in patients with diabetic nephropathy treated for hypertension compared to $20 \%$ in healthy subjects. The same pattern has been found in patients with long-term diabetes without nephropathy [16]. Hornung et al. [17] selected patients with and without autonomic neuropathy and found a loss of diurnal rhythm in those with neuropathy. Wiegman et al. [3] also studied patients with long-term diabetes and found a lack of diurnal variation of blood pressure. In the latter study, patients with albuminuria had not been excluded. Visceral neuropathy with autonomic denervation is an attractive explanation for the nocturnal hypertension. In non-diabetic patients with severe autonomic neuropathy, Mann et al. [18] found no nocturnal decline in blood pressure. The mechanism could be a reduced vagal tone leading to tachycardia and elevated cardiac output. We did not measure the presence of neuropathy in our subjects since probably all patients had some degree of autonomic neuropathy. However, it cannot be excluded that autonomic neuropathy was inequally distributed in the two groups. We found no correlation between day or night heart rate and the night/day blood pressure ratio. This result however, is confounded by beta blocker treatment.

In our study, we found that patients who had an $\mathrm{ECV}$ in the upper range had no nocturnal fall in blood pressure. The patients with an ECV in the lower range had a more normal fall in blood pressure of $9 \%$. When blood pressure values from $4 \mathrm{~h}$ from the middle of the day or night were used, the fall in mean arterial blood pressure was $13 \%$. Although there was a highly significant difference between the two groups regarding night/day ratio, there was an overlap with a resulting low predictive value of ECV determination on the blood pressure variability. The overlap between the groups supports a multifactorial origin as for the nocturnal hypertension.

ECV was determined as the distribution volume of ${ }^{51} \mathrm{Cr}$-EDTA based on the same data used for the determination of the total plasma clearance of ${ }^{51} \mathrm{Cr}$ EDTA. The ${ }^{51} \mathrm{Cr}$-EDTA method has proven to be a simple and fairly accurate method for measuring ECV [8]. We related the ECV to total body mass with no correction for body fat mass. This fact can explain some of the variability and overlap between the groups.

Our data indicate that occult overhydration leads to nocturnal hypertension. The mechanism would be mobilisation of peripheral oedema in the recumbent position leading to an increase in intravascular volume. Another indication of fluid retention associated with loss of nocturnal decline in blood pressure is the finding by Staessen et al. [19] that patients with a blunted nocturnal decline in blood pressure excrete more sodium during the night. Their finding was interpreted as a pressure natriuresis during the night but an alternative explanation is that relative overhydration led to nocturnal loss of sodium. We did not measure sodium excretion but the night-time urine production was higher in the patients with higher ECV. Mathiesen et al. [20] found a tendency towards lower nocturnal blood pressure in patients with diabetic nephropathy treated with captopril and thiazide. Captopril has previously been shown to reduce ECV [21]. In diabetic nephropathy, the degree of overhydration is determined by renal function, amount of proteinuria and doses of diuretics used. The diuretic dose was given according to clinical needs to keep the patients normotensive and free from oedema. The dosage seems to have been well adjusted to the renal function since there was no correlation between ECV and glomerular filtration rate or between ECV and diuretic dose.

The pathological significance of nocturnal hypertension is unclear. There are no reports on the renal consequences of nocturnal hypertension. There is evidence to suggest that when it is present in essential hypertension, there is an increased prevalence of left ventricular hypertrophy, which carries a bad prognosis independent of blood pressure $[22,23]$. Gambardella et al. [24] showed that diabetic patients with autonomic neuropathy and isolated nocturnal hypertension had a $32 \%$ increase in left ventricular mass. We saw a significant correlation between ABP and albu- 
minuria but not with clinic auscultatory blood pressure as previously described [25]. This indicates that ambulatory blood pressure is more informative regarding the blood pressure load on the kidneys. The predictive value however, of ABP for the development of renal function has not been shown.

In conclusion, we have shown that patients with higher ECV have a reduced nocturnal decline in blood pressure. It remains to be determined if a reduction in ECV by means of diuretic treatment can restore a normal day/night blood pressure pattern in patients with diabetes and nephropathy and further diminish the decline in renal function.

Acknowledgements. The study was supported by the Älvsborg County research foundation and the Göteborg Diabetic Association.

\section{References}

1. Parving H-H, Andersen AR, Smidt UM, Hommel E, Mathiesen ER, Svendsen PA (1987) Effect of antihypertensive treatment on kidney function in diabetic nephropathy. BMJ 294: 1443-1447

2. Björck S, Mulec H, Johnsen SA, Nordén G, Aurell M (1992) Renal protective effect of enalapril in diabetic nephropathy. BMJ 304: 339-343

3. Wiegman TB, Herron KG, Chonko AM, Macdougall ML, Moore WV (1990) Recognition of hypertension and abnormal blood pressure burden with ambulatory blood pressure recordings in type I diabetes mellitus. Diabetes 39: 15561560

4. Torffvit O, Agardh C-D (1993) Day and night variation in ambulatory blood pressure in type I (insulin-dependent) diabetes mellitus with diabetic nephropathy and autonomic neuropathy. J Int Med 233: 131-137

5. Hansen KW, Pedersen MM, Marshall SM, Christiansen JS, Mogensen CE (1992) Circadian variation of blood pressure in patients with diabetic nephropathy. Diabetologia 35: $1074-1079$

6. O'Brien E, O'Malley K (1990) Twenty-four hour ambulatory blood pressure monitoring: a review of validation data. J Hypertension [Suppl 6]: S11-S16

7. Brøchner-Mortensen J (1972) A simple method for the determination of glomerular filtration rate. Scan J Clin Lab Invest 30: 271-274

8. Brøchner-Mortensen J (1980) A simple single injection method for determination of the extracellular fluid volume. Scan J Clin Lab Invest 40: 567-573

9. Brøchner-Mortensen J (1992) The extracellular fluid volume in normal man determined as the distribution volume of $\left.{ }^{51} \mathrm{Cr}\right]$ EDTA. Scan J Clin Lab Invest 42: 261-264

10. Staessen JA, Fagard FH, Lijnen PG, Lutgarde T, Van Hoof $\mathbf{R}$, Amery AK (1991) Mean and range of the ambulatory pressure in normotensive subjects from a meta-analysis of 23 studies. Am J Cardiol 67: 723-727
11. Shaw DB, Knapp MS, Davies DH (1963) Variations in blood pressure in hypertensives during sleep. Lancet I: 797:798

12. Littler WA, Honour AJ, Carter RD, Sleight P (1975) Sleep and blood pressure. BMJ 3: 346-348

13. Pickering TG, Harshfield GA, Kleinert HD, Blank S, Laragh JH (1982) Blood pressure during normal daily activities, sleep and exercise. Comparison of values in normal and hypertensive subjects. JAMA 247: 992-996

14. Moore WV, Donaldson DL, Chonko AM, Ideus P, Wiegmann TB (1992) Ambulatory blood pressure in type I diabetes mellitus. Comparison to presence of incipient nephropathy in adolescents and young adults. Diabetes 41: 1035-1041

15. Pickering TG (1991) Characterization of blood pressure variations with ambulatory monitoring. In: EO Brien, KO Mally (eds) Handbook of Hypertension, Vol 14: Blood pressure measurement. Elsevier Science Publishers, B.V. Amsterdam

16. Rynkiewicz A, Furmanski J, Narkiewicz K, Semetkowska E, Bieniaszewski L, Horoszek-Maziarz S, Krupa-Wojciechowska B (1993) Influence of duration of type 1 (insulindependent) diabetes mellitus on 24-h ambulatory blood pressure and heart rate profile. Diabetologia 36: 577 [letter]

17. Hornung RS, Mahler RF, Raftery EB (1989) Ambulatory blood pressure and heart rate in diabetic patients: an assessment of autonomic function. Diabet Med 6: 579-585

18. Mann S, Altman DG, Raftery EB, Bannister R (1983) Circadian variation of blood pressure in autonomic failure. Circulation 68: 477-483

19. Staessen JA, Birkenhager W, Bulpitt CJ et al. (1993) The relationship between blood pressure and sodium and potassium excretion during the day and the night. J Hypertension 11: $443-447$

20. Mathiesen ER, Hommel E, Giese J, Parving H-H (1991) Efficacy of captopril in postponing nephropathy in normotensive insulin dependent diabetic patients with microalbuminuria. BMJ 303: 81-87

21. Hommel E, Parving HH, Mathiesen E, Edsberg B, Damkjær Nielsen, Giese J (1986) Effect of captopril on kidney function in insulin-dependent diabetic patients with nephropathy. BMJ 293: 467--470

22. Koren MJ, Devereux RB, Casale PN, Savage DD, Laragh JH (1991) Relation of left ventricular mass and geometry to morbidity and mortality in uncomplicated essential hypertension. Ann Int Med 114: 345-352

23. Pickering TG, Devereux RB (1987) Ambulatory monitoring of blood pressure as a predictor of cardiovascular risk. Am Heart J 114: 925-928

24. Gambardella S, Frontoni S, Spallone V et al. (1993) Increased left ventricular mass in normotensive diabetic patients with autonomic neuropathy. Am J Hypertension 6: 97-102

25. Hansen KW, Christensen CK, Andersen PH, Pedersen MM, Christiansen JS, Mogensen CE (1992) Ambulatory blood pressure in microalbuminuric type 1 diabetic patients. Kidney Int 41: 847-854 